\title{
Medical School Applicants' Online Interviews during COVID-19 Epidemic
}

\author{
Mariwan Husni, Reginald Sequeira, and Abdelhalim Deifalla
}

\section{ABSTRACT}

\begin{abstract}
Background: For many years, the primary criterion used to select medical school applicants worldwide has been cognitive measures of high school educational attainment. Yet academic assessment alone may not necessarily select the candidates who possess the behavioral or non-cognitive attributes thought important in medical students and doctors: honesty, integrity, flexibility, motivation, willingness to cooperate, managing emotions, selfesteem, control, leadership skills, resilience personal values, confidence, empathy, conscientiousness, and social accountability. There is evidence that significant relationship exists between both cognitive and non-cognitive variables and students' performance in medical school. The challenge posed by the current pandemic of covid19 is that all admission interviews are now carried out via video.
\end{abstract}

Method: In video interviews for admission to our Arabian Gulf University, the applicants were asked standardized questions under four main domains: motivation and commitment to medicine, handling stress and ethical dilemma, social skills, and responsibility as well as self-presentation. Each of these domains was given a Likert score ranging from one to five. Scores 1 and 2 indicated unsatisfactory performance, while scores 3, 4 and 5 indicated fair, good, and excellent, respectively. Each panel member scored each applicant independently. This creates the data bases for statistical analyses.

Results and Discussion: The feedback from staff and students was so far positive, however, statistical results need a longitudinal follow-up of at least one decade: we do not have statistics showing to what extent the selection criteria for admission have a predictive validity for successfully completing the MD program and performing as a medical doctor.

Conclusions: Transitioning medical school interviews to a virtual setting beyond the restrictions of COVID-19 would allow eliminating travel expenses and cost saving for applicants.

Keywords: Medical School Interviews, COVID-19 Epidemic, Applying to Medical Schools, Video Assessment.
Submitted : February 21, 2021

Published : March 15, 2021

ISSN: $2593-8339$

DOI: $10.24018 /$ ejmed.2021.3.2.731

\section{Husni*}

College of Medicine and Medical Sciences, Arabian Gulf University, Kingdom of Bahrain.

(e-mail: mariwanh@agu.edu.bh)

R. Sequeira

College of Medicine and Medical

Sciences, Arabian Gulf University,

Kingdom of Bahrain.

(e-mail: sequeira@agu.edu.bh)

A. Deifalla

College of Medicine and Medical

Sciences, Arabian Gulf University, Kingdom of Bahrain.

(e-mail: ahaleemfd@agu.edu.bh)

*Corresponding Author

\section{INTRODUCTION}

Over the last 25 years a large body of research has investigated how best to select applicants to study medicine [1]. It is agreed that an applicant who is motivated and has knowledge of the profession through experience and a propensity for community service will most likely succeed as a medical student. The process for admission to medical schools has to be fair to the applicants who are a diverse group of people, and to the society by choosing people with the potential to be good doctors.

The COVID-19 pandemic has upended nearly every aspect of undergraduate medical education. The unsettling disruption of the pandemic to the admissions cycle may amplify already intimidating barriers of lower- socioeconomic status (SES) students to educational mobility. The pandemic has brought to the forefront issues that negatively affect socioeconomically disadvantaged applicants' success in medical school admissions [2].

Virtual interviews [3] can be high-yield, positive, and equitable for all applicants and medical schools. It is important to develop a detailed plan with adequate preparation for the interview process, including using standardized interview questions, recognize and respond to potential biases that may be amplified with the online interview format.

A flexible admission process alleviates the financial burden to the applicants, which contributes to the development of a diverse workforce and promotes social accountability principles [4]. 
For many years, the primary criterion used to select medical school applicants worldwide has been cognitive measures of high school educational attainment. This approach raised concerns that academic assessment alone may not necessarily select the candidates who possess the behavioural or non-cognitive attributes thought desirable in medical students and doctors [5].

In response to these challenges, the importance of using both cognitive and noncognitive criteria in selecting applicants is widely accepted. Most medical schools, value non-cognitive traits when making admissions-related decisions. Non-cognitive attributes such as honesty, integrity, flexibility, motivation, willingness to cooperate, managing emotions, self-esteem, control, leadership skills, resilience personal values, confidence, empathy, conscientiousness, and social accountability are fundamental qualities for good medical practice [6]. Intellectual ability to do the job, maintaining diversity of skills and personality are characteristics that are required in any doctor. There is evidence that significant relationship exists between both cognitive and non-cognitive variables and students' performance in medical school [7].

Medical schools in some countries like the United States and Canada are usually accepting graduate entrants (GE), which means that the applicants after they finish high school at 17 or 18 years of age enrol in preclinical university courses, which are mostly general rather than subject specific. They are most likely have obtained a Bachelor of Arts or Sciences (BA or BS) degree prior to attending medical school, which is a further 4 years including 2 years of classroom sciences and 2 years of ward-based training in most of the specialties. Then they graduate with the Doctor of Medicine (MD) degree [8]. However, medical schools in the United Kingdom (UK), Australia and Kingdom of Saudi Arabia, are accepting school leaver entrants (SLE), who are usually 17- or 18-year-old. These schools are running programs for at least 5/6 years duration and they award Bachelor of Medicine, Bachelor of Surgery (e.g., MB BS) [9]. Arabian Gulf University (AGU), however, awards MD degree after successful completion of a six- year program.

In 1997, the UK Medical Workforce Standing Advisory Committee recommended that one way of diversifying the medical student population was to attract graduate students, with more life experience, into medical schools [10]. This recommendation led several universities in the UK develop graduate level courses and the first 4-year graduate entry (GE) medical course started in 2000. The UK medical schools also started to assess non-cognitive qualities of applicants by using aptitude tests as a supplementary selection technique.

The two aptitude tests for the UK undergraduate medical schools are the University Clinical Aptitude Test (UCAT) [11] and the Biomedical Admissions Test (BMAT) [12]. The aptitude test required for the UK graduate programs' entrance is Graduate Medical School Admissions Test (GAMSAT) [13]. In other countries like the United States (USA), Canada and 15 other countries the entrance aptitude test required is the Medical College Admission Test (MCAT) [14].

Medical schools across the US and other countries are receiving just as many applications now as they did before the COVID-19 pandemic started. According to the Association of American Medical colleges (AAMC), some medical schools report an increase of the applications received for admission by approximately $17 \%$ [15].

Some "pre-med" students say the coronavirus outbreak has solidified their desire to enter the medical profession because they want to help address the health care challenges that the crisis has exposed, such as a lack of preparedness for controlling the spread of infectious diseases [16].

Due to COVID-19 pandemic situation conducting all interviews online with applicants to American medical colleges is strongly encouraged. Online interviews are conducted by majority of medical schools in the world, to abide by social distancing recommendations and to support the public health efforts to limit the spread of COVID-19 disease [17]. These efforts are supported by all the international organizations concerned with medical education such as the Association of American Medical colleges (AAMC). Online interview is a solution to ensure the selection process is satisfactory in selection of medical school applicants, as it has been adopted by technology companies in their recruitment process due to travel restrictions and to prevent COVID-19 spread [18].

The AGU students are mainly from Saudi Arabia, Kuwait, and Bahrain. There are fewer students from Oman, United Arab Emirates and Qatar. All students are recent graduates from the high the school in their perspective countries. More than $80 \%$ of students are coming from governmental secondary schools but few have had private secondary education in their countries. Ministries of education of their countries sponsor most the AGU students.

In previous years students progressed to year 1 if they did well on IELTS and achieved the 6 or above. This year almost sixty students of a total 70 progressed from the foundation year to year one.

This year (2020), AGU received 349 online applications to study medicine, compared to 242 applicants in the previous year (2019). Like previous years, two thirds of the applicants were females. This year the AGU interviewed 209 applicants online by using zoom teleconferencing, after successfully completing online written entrance tests.

\section{METHOD}

The online interview aimed to evaluate the personality traits and qualities of the candidates to determine each applicant's suitability to study medicine and to assess the extent to which he/she will be suited to the Problem Based Learning (PBL) study program at the AGU. PBL programs are dependent on problem-solving abilities, and the extent to which the students can rely on self-learning.

Each interview lasted for fifteen minutes, during which the applicant met a panel comprised of two experienced senior faculty members and a sixth-year medical student. At least one member of each panel was fluent in Arabic Language.

Just before commencing interviews with the applicants, each panel met and agreed a unified approach to ensure that the questions to be asked were consistent and that all interviewees were evaluated based on the same criteria and standards.

The applicants were asked standardized questions under four main domains: motivation and commitment to medicine, handling stress and ethical dilemma, social skills, and 
responsibility as well as self-presentation. Each of these domains was given a Likert score ranging from one to five. Scores 1 and 2 indicated unsatisfactory performance, while scores 3,4 and 5 indicated fair, good, and excellent, respectively. Each panel member scored each applicant independently.

\section{RESUlTS AND DISCUSSION}

The interview process went very smoothly, and the informal feedback was positive. We did not have any complaints by the applicants. The faculty who had participated in previous years' face-to-face interviews were satisfied that the online interviews were as effective to select the appropriate applicants to study medicine at the AGU.

The extent to how the selection process including the Aptitude Test and the Entrance Test successfully correlate with Intermediate progress at medical schools and predicting performance as a doctor after graduation and during postgraduate (residency) training is not robust [19]. This is also likely to be applicable to the AGU selection process, because we do not have statistics showing to what extent the selection criteria for admission have a predictive validity for successfully completing the MD program and performing as a medical doctor.

It is widely accepted that the interview is the most important factor in selection [20]. There are two types of interviews that medical schools use to select students are panel interviews (PI) or multiple mini-interviews (MMIs) [21]. The AGU online interviews, like previous years in person attending interviews, were panel interviews (PI) in which multiple interviewers evaluated an applicant during a single observation [22]. PI has poor context specificity because situational factors affect performance more than true ability. Therefore, many medical schools have moved to highly reliable (MMIs), which are a series of focused and highly structured stations or encounters with separate interviewers [23]. Currently, MMI is used in Canada, UK and more than 30 medical schools across the United States. There are experiences described about their use in universities of Asia, Oceania [24] and South America [25], Variable number of MMI stations (5-12), number of raters per station (1-2) and time of the interview (5-12 min) did not impact the outcome. The number of stations seems more relevant than the number of raters for reproducibility of the results [26]. The importance of training raters is well recognized.

Most public universities have social and affirmative action programs. Because of the highly competitive process of medical school admissions, the inclusion of a subjective assessment in the form of MMI raises concerns as regard to potential disadvantages to applicants from disadvantaged socio-economic-linguistic background. The program accreditation agencies, such as the Liaison Committee on Medical Education has two standards pertaining to diversity and inclusion [27]. Medical school must develop programs or partnership aimed at broadening diversity among qualified applicants for medical school admissions and have explicit policies and practices to achieve appropriate diversity among students. The role and effects of racial aggregation in health professions education is increasingly coming under scrutiny [28]. Among the social accountability frameworks of medical schools, the diversity of student selection has been emphasized [29].

A study at the University of Sydney in Australia compared online MMIs interviews of their international applicants to the local applicants continued using traditional in person MMI. They found that there were no significant differences between the scores of the two groups, indicating that the online version of the MMI is comparable to the in-person MMI [30]. Our experience using the PI model of interviewing appears to be having no significant difference of scoring of this year's (2020) cohort of applicants comparing to previous years' applicants.

\section{CONCLUSIONS}

A consideration to transitioning medical school interviews to a virtual setting beyond the restrictions of COVID-19 would allow eliminating travel expenses and cost saving [31] for applicants such as those who apply to the CMMS, AGU from various GCC countries.

\section{REFERENCES}

[1] Kreiter CD, Axelson RD. A perspective on medical school admission research and practice over the last 25 years. Teaching and Learning Medicine. 2013;25 Suppl 1:S50-6.

[2] Perez M, Williams C, Vapiwala N. "Holistic Admissions" During a Pandemic: The Effects of COVID-19 on Socioeconomically Disadvantaged Medical School Applicants. Academic Medicine. 2021 Jan 1;96(1):e3-e4. doi: 10.1097/ACM.0000000000003613. PMID: 32769448).

[3] Huppert LA, Hsiao EC, Cho KC, Marquez C, Chaudhry RI, Frank J, Goglin SE, Hsu G, Kathpalia P, Khanna R, Kompala T, Rao MN, Bower BA, Trafas VMS, Santhosh L, Schwartz BS, Babik JM. Virtual Interviews at Graduate Medical Education Training Programs. Academic Medicine. December 8, 2020 - Published Ahead of Print. doi: 10.1097/ACM.0000000000003868.

[4] Ballejos MP, \& Sapien R. Medical School Admissions and Enhancing Holistic Review Practices During COVID-19. Academic Medicine. 2020;95(11), e5-e6 https://doi.org/10.1097/ACM.0000000000003578.

[5] McManus IC, Dewberry C, Nicholson S, Dowell JS. The UKCAT-12 study: educational attainment, aptitude test performance, demographic and socio-economic contextual factors as predictors of first year outcome in a cross-sectional collaborative study of 12 UK medical schools. BMC Medicine. 2013;11(1):244-244.

[6] Finn GM, Mwandigha L, Paton LW, \& Tiffin PA. The ability of 'noncognitive' traits to predict undergraduate performance in medical schools: a national linkage study. BMC Med Educ. 2018;18(1):93. https://doi.org/10.1186/s12909-018-1201-7.

[7] de Visser M, Fluit C, Cohen-Schotanus J, Laan R. The effects of a noncognitive versus cognitive admission procedure within cohorts in one medical school. Advances in Health Sciences Education: Theory and Practice. 2018 Mar;23(1):187-200. doi: 10.1007/s10459-017-9782-1.

[8] Smedley BD, Stith AY, Colburn L, et al. The Right Thing to Do, The Smart Thing to Do: Enhancing Diversity in the Health Professions: Summary of the Symposium on Diversity in Health Professions in Honor of Herbert W.Nickens, M.D. Washington (DC): National Academies Press (US), 2001.

[9] Marsden JS. An insider's view of the American and UK medical systems. British Journal of General Practice. 2006;56(522):60-62.

[10] Devine OP, Harborne AC, McManus IC. Assessment at UK medical schools varies substantially in volume, type and intensity and correlates with postgraduate attainment. BMC Medical Education. 2015;15:146.

[11] Kumwenda B, Cleland J, Greatrix R, MacKenzie RK, Prescott G. Are efforts to attract graduate applicants to UK medical schools effective in increasing the participation of under-represented socioeconomic groups? A national cohort study. BMJ Open. 2018;8(2): e018946.

[12] hUCAT | UCAT Consortium. (2020). Retrieved 7 November 2020, from https://www.ucat.ac.uk/ucat. 
[13] Test-takers, F. (2020). BMAT | Cambridge Assessment Admissions Testing. Retrieved 7 November 2020, from https://www.admissionstesting.org/for-test-takers/bmat.

[14] Graduate Medical School Admissions Test | GAMSAT | ACER. (2020). Retrieved 7 November 2020, from https://gamsat.acer.edu.au/research1.

[15] Register for the MCAT Exam. (2020). Retrieved 7 November 2020 , from https://students-residents.aamc.org/applying-medicalschool/taking-mcat-exam/register-mcat-exam.

[16] Weiner S. Applications to medical school are at an all-time high. What does this mean for applicants and schools? American Association of Medical Colleges (AAMC), 2020. Retrieved 7 November 2020, from https://www.aamc.org/news-insights/applications-medical-school-areall-time-high-what-does-mean-applicants-and-schools.

[17] How coronavirus could affect medical school admissions? (2020). $\begin{array}{lllll}\text { Retrieved } & 7 & \text { November } & 2020, & \text { from }\end{array}$ https://www.usnews.com/education/best-graduate-schools/topmedical-schools/articles/how-coronavirus-could-affect-medicalschool-admissions.

[18] Interviews | Medical Schools Council, 2020. Retrieved 7 November 2020, from https://www.medschools.ac.uk/studyingmedicine/interviews.

[19] Harper J. Coronavirus: job interviews go online as candidates stuck at home. BBC News. March 16 2020. https://www.bbc.com/news/business-51847888; accessed 30 October 2020.

[20] Khan J, Tabasum S, Mukhtar O. Comparison of pre-medical academic achievement, entrance test and aptitude test scores in admission selection process. Journal of Pakistan Medical Association. 2013; 63(5):552-7.

[21] Pau A, Chen YS, Lee VK, Sow CF, De Alwis R. What does the multiple mini interview have to offer over the panel interview?. Medical Education Online. 2016;21:29874. doi:10.3402/meo.v21.29874.

[22] Chami G. The changing dynamic of medical school admissions. Canadian Medical Association Journal. 2010;182:1833-4.

[23] Albanese MA, Snow MH, Skochelak SE, Huggett KN, Farrell PM. Assessing personal qualities in medical school admissions. Academic Medicine. 2003;78:313-21.

[24] Hanson MD, Woods NN, Martimianakis MA, Rasasingham R, Kulasegaram K. Multiple independent sampling within medical school admission interviewing: an 'intermediate approach'. Perspectives on Medical Education. 2016;5:292-9.

[25] Says F, Ayuob, N, Fahmy AR, Fayez F, Hasanian M, Deek B. Experience of establishment of multiple mini structure interviews as part of student admission policy at Faculty of Medicine, King Abdulaziz University, 2011-2012. Medical Teacher. 2013;35(Suppl):S74-S77.

[26] Daniel-Filho DA, Pires EMSG, Paes AT, Troster EJ, Silva SCABS, Granato MF, Couto TB. First experience with multiple mini interview for medical school admission in Brazil: Does it work in a different cultural scenario? Medical Teacher. 2017;39:1033-1039.

[27] Rees EL, Hawarden AW, Dent G, Hays R, Bates J, HassellAB. Evidence regarding the utility of multiple mini-interview (MMI) for selection to undergraduate health programs: a BEME systematic review. BEME Guide No. 37. Medical Teacher. 2016; 38:443-455.

[28] Boatright DH, Samuels EA, Cramer L, et al. Association Between the Liaison Committee on Medical Education's Diversity Standards and Changes in Percentage of Medical Student Sex, Race, and Ethnicity. JAMA. doi:10.1001/jama.2018.13705.

[29] Weiss RL. Belonging, respectful inclusion, and diversity in medical education. Academic Medicine. 2020; 95: 661-664.

[30] Cassandra B, van der Vleuten C, Leppink J, Saad C. Social accountability framework and their implications for medical education and program evaluation. Academic Medicine. 2020; doi: 10.1097/ACM.0000000000003731 (Published ahead of print).

[31] Tiller D, O’Mara D, Rothnie I, Dunn S, Lee L, Roberts C. Internetbased multiple mini-interviews for candidate selection for graduate entry programmes. Medical Education. 2013; 47:801-810.

[32] Rosenfeld JM, Reiter HI, Trinh K, Eva KW. A cost efficiency comparison between the multiple mini-interview and traditional admissions interviews. Advances in Health Sciences Education. 2008;13:43-58.
M. Husni is Professor and Chairperson of Psychiatry Department. College of Medicine and Medical Sciences, Arabian Gulf University, Kingdom of Bahrain.

He oversaw the local postgraduate training in psychiatry at Northwick Park Hospital and the director of the MRCPsych course, Charing Cross Training Scheme, London, UK. He has served as an external advisor on the Annual Review Panels (ARCP) for the Royal College of Psychiatrists, for core and specialty training in psychiatry.

Reginald P. Sequeira is Professor and Former Chair of Department of Pharmacology \& Therapeutics, Arabian Gulf University. He is a member of WHO Collaborating Centre for Health Professionals Educational Development, College of Medicine \& Medical Sciences, Arabian Gulf University, Kingdom of Bahrain.

A. Deifalla is Dean, College of Medicine \& Medical Sciences and Professor at the Anatomy Department, Arabian Gulf University, Kingdom of Bahrain. He is the Director of the WHO Collaborating Centre for Health Professionals' Education Development, College of Medicine \& Medical Sciences, Arabian Gulf University, Kingdom of Bahrain. 